\title{
PENGGUNAAN JAMBAN SANITER DI JORONG UBA KENAGARIAN KOTO TANGAH KECAMATAN TILATANG KAMANG
}

\author{
Fitria Fatma', Vebby Junefla Aprilia Putra ${ }^{2}$ \\ 1’2 Program Studi Ilmu Kesehatan Masyarakat, STIKes Fort De Kock Bukittinggi \\ email fitriafatma1986@ gmail.com ${ }^{1}$
}

Submitted : 23-12-2016, Reviewer: 26 -01-2017, Accepted : 14 -10-2017

\begin{abstract}
ABSTRAK
Data Dinas Kesehatan Propinsi Sumatera Barat tahun 2014 menunjukkan 48,2 \% masyarakat di Sumatera Barat yang memiliki tempat pembuangan tinja saniter. Tujuan Penelitian ini adalah untuk mengetahui faktor-faktor yang berhubungan dengan penggunaan jamban saniter di Jorong Uba Kenagarian Koto Tangah Kecamatan Tilatang Kamang Kabupaten Agam Tahun. Jenis penelitian deskripsi analitik dengan desain penelitian Cross Sectional. Dilaksanakan pada bulan Agustus September 2016 di Jorong Uba Kenagarian Koto Tangah Kecamatan Tilatang Kamang Kabupaten Agam dengan jumlah sampel 61 responden dan pengambilan sampel dengan teknik Random Sampling. Sampel 61 responden. Analisis data menggunakan analisis univariat dan analisis bivariat dengan Chi-Square. Hasil penelitian ditemukan dari 61 responden terdapat 31 responden $(50.8 \%)$ responden memiliki pengetahuan tinggi, 34 responden $(55.7 \%)$ bersikap baik ,46 responden $(75.4 \%)$ petugas kesehatan berperan dan 33 responden $(54.1 \%)$ menggunakan jamban saniter. Hasil uji statistik $p=0,015$ untuk hubungan pengetahuan dengan penggunaan jamban saniter, $p=0,034$ untuk hubungan sikap dengan penggunaan jamban saniter dan $p=0,119$ untuk hubungan peranan petugas kesehatan dengan penggunaan jamban saniter. Hubungan yang bermakna antara pengetahuan dan sikap dengan penggunaan jamban saniter, sedangkan peranan petugas kesehatan tidak berhubungan dengan penggunaan jamban saniter..
\end{abstract}

Kata Kunci : Jamban Saniter, perilaku

\begin{abstract}
Environmental sanitation in Indonesia in general and in particular the province of West Sumatra still has not achieved adequate sanitary conditions. Basic sanitation needs have not been met as the development of human waste disposal. Based on the data obtained from West Sumatra Health Office in 2014 showed that only $48.2 \%$ of households in West Sumatra has its decent toilet. The purpose of this study was to determine the factors associated with the use of sanitary latrine in the elliptic uba districts koto tangah districs tilatang kamang district agam in 2016. This research is an analytic description of the cross-sectional design. Held in August - september 2016 in the elliptic uba districts koto tangah districs tilatang kamang district agam with a sample of 61 respondents and a sampling method with random sampling techniques. The data were obtained from the questionnaires by 61 respondents. The data analysis used univariate and bivariate analysis. Statistical tests was performed by Chi-Square. From the results of the research of 61 people found 31 respondents $(50.8 \%)$ had high knowledge , 34 respondents (55.7\%) are good , 46(75.4\%) health workers participated and 33 respondents $(54.1 \%)$ sanitary latrines. The results of statistical tests $p=0.015$ for the relationship of knowledge with a the use of sanitary latrines, $p=0.034$ for the relationship of attitude with a the use of sanitary latrines and $p=0.119$ for the relationships of health workers role with a the use of sanitary latrines.It can be concluded from the study that there is a significant relationship between knowledge and attitudes with a the use of sanitarylatrines, while the role of health workers is not related to the use of sanitary latrines. So, the health officers are expected to be more maximal in persuading people to use sanitary latrines.
\end{abstract}

Keyword $\quad$ : Sanitary Latrines, Behaviour 


\section{PENDAHULUAN}

Badan Kesehatan Dunia (WHO) mengatakan, peningkatan akses terhadap air bersih, sanitasi, dan perilaku hidup bersih akan menurunkan angka kejadian diare hingga 94\%. Berkurangnya angka diare akan meningkatkan produktivitas dan pendapatan masyarakat. Studi Bank Dunia menyebutkan negara akan mengalami kerugian setara $\mathrm{Rp} 58$ triliun per tahun akibat sanitasi yang buruk.

Derajat kesehatan dipengaruhi oleh beberapa faktor yaitu lingkungan, perilaku, pelayanan medis, dan keturunan. Lingkungan merupakan faktor yang besar pengaruhnya terhadap kesehatan individu dan masyarakat. Keadaan lingkungan yang tidak memenuhi persyaratan kesehatan dan perilaku masyarakat dapat merugikan kesehatan baik masyarakat dipedesaan maupun perkotaan yang disebabkan karena kurangnya pengetahuan dan kemampuan masyarakat dibidang kesehatan, ekonomi, maupun teknologi. Kondisi lingkungan yang berpengaruh terhadap kesehatan tersebut adalah penyediaan air bersih, penyediaan jamban keluarga, kondisi rumah dan kondisi lingkungan pemukiman (Depkes RI 2007).

Lingkungan yang diharapkan adalah lingkungan yang kondusif bagi terwujudnya keadaan sehat, yaitu lingkungan yang bebas dari polusi, tersedianya air bersih, sanitasi lingkungan yang memadai, perumahan, pemukiman yang sehat, perencanaan kawasan berwawasan kesehatan, serta terwujudnya kehidupan masyarakat yang saling tolong menolong dalam memelihara nilai-nilai budaya bangsa. Lingkungan mempunyai dua unsur pokok yang sangat erat terkait satu sama lain yaitu unsur fisik dan sosial (Depkes RI 2009).

Penggunaan jamban yang disertai partisipasi keluarga akan baik, bila didukung oleh beberapa faktor. Diantaranya faktor yang berasal dari dalam diri individu disebut factor internal seperti pendidikan, pengetahuan, sikap, tindakan atau kebiasaan, pekerjaan, pendapatan, jenis kelamin, umur, suku dan sebagainya. Adapun faktor dari luar dari individu disebut faktor eksternal seperti fasilitas jamban baik meliputi jenisnya, kebersihannya, kondisinya, ketersediannya termasuk kecukupan air bersihnya dan pengaruh lingkungan seperti penyuluhan oleh petugas kesehatan termasuk tokoh adat dan agama tentang penggunaan jamban sehat (Depkes RI, 2005).

Jamban keluarga atau yang dikenal dengan istilah kakus/WC adalah tempat yang dipakai oleh manusia untuk membuang hajat. Berdasarkan petunjuk dari DepKes RItelah diketahui bahwa tinja merupakan sumber pencemaran yang dapat menimbulkan dan menularkan penyakit kepada manusia seperti mutaber, mencret, typhus, disentry, cacingan, gatal-gatal dan sebagainya. Dengan demikian jelas bahwa menggunakan jamban untuk mencegah terjadinya penularan penyakit dan pencemaran kotoran manusia. Jamban atau sarana pembuangan kotoran yang memiliki syarat adalah upaya penyehatan lingkungan pemukiman. Sarana jamban yang tidak saniter berperan terhadap kesehatan masyarakat dan lingkungan. Yang dapat mengakibatkan terjadinya bibit penyakit dan mengganggu estetika lingkungan (DepKes RI. 2010).

$$
\text { Keputusan menteri nomor }
$$

825/2008 tentang Strategi Nasional Sanitasi Total Berbasis Masyarakat disebutkan bahwa jamban sehat adalah fasilitas pembuangan tinja yang efektif untuk memutuskan mata rantai penularan penyakit.Sanitasi lingkungan di Indonesia pada umumnya dan Propinsi Sumatera Barat pada khususnya masih belum mencapai kondisi sanitasi yang memadai. Kebutuhan sanitasi dasar belum tercapai seperti pembangunan tempat pembuangan kotoran manusia. Fasilitas pembuangan tinja/pembuangan kotoran manusia yang memenuhi syarat kesehatan berpengaruh 
besar terhadap kesehatan lingkungan. Berdasarkan data yang diperoleh dari Dinas Kesehatan Republik Indonesia tahun 2014 terdapat $61,06 \%$ rumah tangga yang memiliki akses sanitasi layak dan 38,94\% rumah tangga tidak memiliki sanitasi yang layak.Dari data Provinsi Sumatra Barat bahwa cakupan jamban untuk tahun 2014 baru mencapai $48,2 \%$ masyarakat dengan akses jamban yang layak dan saniter, dimana semua masyarakat seharusnya memiliki jamban yang sehat (saniter) agar tidak terjadi penyebaran penyakit yang diakibatkan oleh tinja.

Dari data yang diperoleh dari Dinas Kesehatan Kabupaten Agam tahun 2014 terdapat $78 \%$ yang memiliki akses jamban yang layak dan saniter, sarana jamban yang ada meliputi komunal dan leher angsa. Jumlah sarana jamban jenis komunal yang ada yaitu 2.447 jamban dengan jumlah penduduk pengguna sebanyak 46.498 orang. Dari jumlah yang ada tersebut, yang memenuhi yaitu sebanyak 2.074 jamban dengan jumlah penduduk pengguna 82.951 orang $(56,05 \%)$. Berdasarkan data dari puskesmas setempat jumlah pengguna jamban di jorong uba terdapat 63\% penduduk pengguna jamban, $37 \%$ penduduk yang akses BAB nya dilakukan di kolam/parit. Sementara itu di temukan

\section{METODE PENELITIAN}

Jenis penelitian ini adalah kualitatif dan desain penelitian bersifat deskriptif analitik dengan pendekatan Cross Sectional Study. Penelitian ini dilaksanakan di Jorong Uba Kenagarian Koto Tangah Kecamatan Tilatang Kamang Kabupaten Agam pada Tanggal 29 Agustus - 3 September Tahun 2016. Populasi pada penelitian ini adalahs emua Kepala Keluarga (KK) sebanyak 159 KK di Jorong Uba Tahun 2016. Sampel adalah semua Kepala Keluarga (KK) yang memiliki jamban di Jorong Uba Kenagarian Koto Tangah Kecamatan Tilatang Kamang Kabupaten Agam Tahun 2016 yang memenuhi kriteria inklusi dan ekslusi

\section{HASIL DAN PEMBAHASAN}

Sebanyak 159 kasus diare di wilayah kerja Puskesmas Pakan Kamis Tahun 2015. Seperti yang kita ketahui bahwa salah satu penyebab terjadinya penyakit diare dikarenakan pembuangan tinja yang tidak saniter atau tidak memenuhi syarat kesehatan. Berdasarkan uraian diataspeneliti tertarik untuk melakukan penelitian tentang "faktor-faktor apa saja yang berhubungan dengan penggunaan jamban saniter di Jorong Uba Kenagarian Koto Tangah Kecamatan Tilatang Kamang Kabupaten Agam Tahun 2016".

Tabel 1

Faktor yang Berhubungan dengan Penggunaan Jamban Saniter

\begin{tabular}{|c|c|c|c|c|c|c|c|c|}
\hline \multicolumn{8}{|c|}{ Penggunaan Jamban Saniter } & \\
\hline & \multicolumn{2}{|c|}{ Tidak saniter } & \multicolumn{2}{|c|}{ Saniter } & \multirow[b]{2}{*}{$\mathrm{n}$} & \multirow[b]{2}{*}{$\%$} & & \\
\hline & $\mathrm{n}$ & $\%$ & $\mathrm{~N}$ & $\%$ & & & & \\
\hline \multicolumn{9}{|l|}{ Pengetahuan } \\
\hline Rendah & 19 & 63,3 & 11 & 36,7 & 30 & 100 & \multirow[t]{2}{*}{0,015} & 4,222 \\
\hline Tinggi & 9 & 29 & 22 & 71 & 31 & 100 & & $(1,443-12,355)$ \\
\hline \multicolumn{9}{|l|}{ Sikap } \\
\hline Kurang Baik & 17 & 63 & 10 & 37 & 27 & 100 & \multirow{2}{*}{0,034} & 3,555 \\
\hline Baik & 11 & 32,4 & 23 & 67,6 & 34 & 100 & & $(1,230-10,273)$ \\
\hline \multicolumn{9}{|c|}{ Peranan Petugas Kesehatan } \\
\hline Tidak Berperan & 10 & 66,7 & 5 & 33,3 & 15 & 100 & \multirow{2}{*}{0,119} & 3,111 \\
\hline Berperan & 18 & 39,1 & 28 & 60,9 & 46 & 100 & & $(0,913-10,601)$ \\
\hline
\end{tabular}




\section{Hubungan Pengetahuan Penggunaan Jamban Saniter}

Dari hasil penelitian terhadap 61 orang diperoleh dari 30 responden yang berpengetahuan rendah terdapat 19 (63.3\%) responden yang tidak menggunakan jamban saniterdan dari 31 responden yang berpengetahuan tinggi terdapat 9 (29.0\%) responden yang tidak menggunakan jamban saniter.

Hasil uji Statistik diperoleh $\mathrm{p}=0.015$ ( $\mathrm{p}<0,05)$, maka dapat disimpulkan ada hubungan yang bermakna antara pengetahuan dengan penggunaan jamban saniter.

Menurut asumsi peneliti pengetahuan seseorang tentang jamban saniter berhubungan erat dengan tindakan seseorang dalam hal pengetahuan tentang penggunaan jamban saniter dirumah. Bila seseorang mengetahui akibat dari buang air sembarangan maka mereka akan berusaha untuk membuat jamban yang saniter.

Namun hal ini tidak selalu terjadi, meskipun mereka telah mengetahui pentingnya menggunakan jamban saniter, namun karena perilaku yang tidak baik maka masih ada juga yang buang air sembarangan.

Dikarenakan masih terdapatnya pengetahuan masyarakat yang rendah terhadap jamban saniter, oleh sebab itu perlu diadakan penyampaian informasi kepada masyarakat dalam bentuk penyuluhan dengan berbagai metode dan media dari petugas kesehatan supaya masyarat dapat berubah dari yang sebelumnya tidak menggunakan jamban saniter sehingga masyarakat tersebut menggunakan jamban saniter.

\section{Hubungan Sikap Dengan Penggunaan Jamban Saniter}

Dari hasil penelitian terhadap 61 orang diperoleh dari 27 responden yang memiliki sikap kurang baik terdapat 17 (63.0 $\%)$ responden yang tidak menggunakan jamban saniterdan dari 34 responden yang memiliki sikap baik terdapat 11 (32.4\%) responden yang tidak menggunakan jamban saniter.

Hasil uji Statistik diperoleh $\mathrm{p}=0,034$ $(\mathrm{p}<0,05)$, maka dapat disimpulkan ada hubungan yang bermakna antara sikap dengan penggunaan jamban saniter.

Menurutasumsipenelitisikapmemilikiperanan terhadapperilakuhidupseseorang.Semakin

baik sikap seseorang maka semakin baik dalam bertindak. Misalnya, Sewaktu menghadiri penyuluhan tentang kesehatan. Seseorang yang memiliki sikap baik terhadap penggunaan jamban saniter maka ia akan mau membuat jamban saniter untuk keluarganya karena jamban merupakan kebutuhan yang penting dan dapatmeningkatkanderajatkesehatan.

Dikarenakan masih terdapat sikap responden yang kurang baik terhadap penggunaan jamban saniter disebabkan karena kebiasaan masyarakat yang Buang Air Besar (BAB) di jamban yang tidak saniter, dimana sebagian besar responden menyatakan bahwa jamban saniter tidak begitu penting untuk dibuat karena masih banyak keperluan lain dan kurangnya biaya dalam pembuatan jamban saniter tersebut, responden cendrung menggunakan jamban yang tidak dilengkapi saluran pembuangan air limbah atau septic tank.

Oleh sebab itu diharapkan tenaga kesehatan yang berlokasi di jorong uba untuk dapat lebih meningkatkan lagi kepedulian masyarakat akan pentingnya menggunakan jamban saniter, karena dengan adanya keinginan masyarakat untuk menggunakan jamban saniter secara tidak langsung akan merubah sikap masyarakat yang sebelumnya lebih mementingkan hal lain dibandingkan jamban saniter mau untuk menggunakan jamban saniter. 
Hubungan peranan petugas kesehatan dengan penggunaan jamban saniter

Dari hasil penelitian terhadap 61 orang terdapat 15 petugas kesehatan tidak berperan terdapat $10(66.7 \%)$ responden yang tidak menggunakan jamban saniter dan dari 46 petugas kesehatan berperan terdapat 18 (39.1\%) responden yang tidak menggunakan jamban saniter.

Hasil uji Statistik diperoleh $\mathrm{p}=0,119$ ( $p>0,05)$, maka dapat disimpulkan tidak ada hubungan yang bermakna antara peranan petugas kesehatan dengan penggunaan jamban saniter.

Untuk berprilaku sehat, masyarakat kadang-kadang bukan hanya perlu pengetahuan dan sikap positif dan dukungan fasilitas saja, melainkan juga perlu dukungan dari keluarga dan petugas kesehatan. Dukungan petugas terutama petugas kesehatan merupakan salah satu pendorong dalam penggunaan jamban saniter. Berdasarkan penggunaan jamban saniter sangat tergantung juga pada petugas kesehatan yang merupakan ujung tombak dalam mempromosikan dan memberikan penyuluhan tentang pentingnya memiliki jamban yang saniter.

Untuk meningkatkan peranan petugas kesehatan dalam memberikan penyuluhan tentang penggunaan jamban yang saniter perlu diberikan pelatihan yang terpadu (pengetahuan dan ketrampilan ) mengenai jamban yang memenuhi syarat kesehatan yang baik dan menggunakan metode dan media yang mudah untuk dipahami masyarakat.

Hal ini tidak sejalan dengan hasil penelitian Vrenda (2013) tentang faktor - faktor yang berhubungan dengan kepemilikan jamban sehat di daerah pinggiran pantai carocok painan kabupaten pesisir selatan.

Menurut asumsi peneliti tidak berhubungannya peran petugas dikarenakan kurang memadainya jumlah petugas kesehatan untuk memberikan penyuluhan secara rutin dan membina masyarakats upaya menggunakan jamban saniter, peranan petugas kesehatan memiliki kedudukan penting terhadap penggunaan jamban saniter, karena dengan adanya peranan petugas kesehatan seperti pemberian penyuluhan tentang jamban saniter, maka dengan secara tidak lansung sudah mendorong keinginan masyarakat tersebut untuk memiliki jamban yang saniter.

Dikarenakan masih terdapatnya tidak berperan petugas kesehatan terhadap penggunaan jamban saniter di jorong uba yang dikarenakan kurang memadainya jumlah petuas pemegang program yang bersangkutan, sebaiknya untuk dapat mencukupi kebutuhan petugas kesehatan agar bisa menjalankan programnya dengan semestinya

\section{SIMPULAN}

Pengetahuan seseorang tentang jamban saniter berhubungan erat dengan tindakan seseorang dalam hal pengetahuan tentang penggunaan jamban saniter dirumah. Bila seseorang mengetahui akibat dari buang air sembarangan maka mereka akan berusaha untuk membuat jamban yang saniter. Namun hal ini tidak selalu terjadi, meskipun mereka telah mengetahui pentingnya menggunakan jamban saniter, namun karena perilaku yang tidak baik maka masih ada juga yang buang air sembarangan.

Dikarenakan masih terdapatnya pengetahuan masyarakat yang rendah terhadap jamban saniter, oleh sebab itu perlu diadakan penyampaian informasi kepada masyarakat dalam bentuk penyuluhan dengan berbagai metode dan media dari petugas kesehatan supaya masyarat dapat berubah dari yang sebelumnya tidak menggunakan jamban saniter sehingga masyarakat tersebut menggunakan jamban saniter.

sikap responden yang kurang baik terhadap penggunaan jamban saniter disebabkan karena kebiasaan masyarakat yang Buang Air Besar (BAB) di jamban yang tidak saniter, dimana sebagian besar 
responden menyatakan bahwa jamban saniter tidak begitu penting untuk dibuat karena masih banyak keperluan lain dan kurangnya biaya dalam pembuatan jamban saniter tersebut, responden cendrung menggunakan jamban yang tidak dilengkapi saluran pembuangan air limbah atau septic tank.

Menurut asumsi peneliti tidak berhubungannya peran petugas dikarenakan kurang memadainya jumlah petugas kesehatan untuk memberikan penyuluhan secara rutin dan membina masyarakats upaya menggunakan jamban saniter, peranan petugas kesehatan memiliki kedudukan penting terhadap penggunaan jamban saniter, karena dengan adanya peranan petugas kesehatan seperti pemberian penyuluhan tentang jamban saniter, maka dengan secara tidak lansung sudah mendorong keinginan masyarakat tersebut untuk memiliki jamban yang saniter.

\section{DAFTAR PUSTAKA}

Abdullah. 2010. Tujuh Syarat Membuat Jamban Sehat. http://sanitasi.or.id/index.php?option=co m. 23 Juni 2013 (18:17).

Anonimous. 2010. Sanitasi Bersih Seksi Penyehatan Lingkungan Dinas Kesehatan Provinsi Jawa Tengah. hhtp://sanitasibersih.blogspot.com/2010/ 09/jamban.html. 12 Juni 2013 (14:50).

Azwar. 1990. Pengantar Ilmu Kesehatan Lingkungan.Jakarta: Mutiara Sumber widya Press. Badan Penelitian dan Pengembangan Kesehatan Departemen Kesehatan RI, 2010.
Chayatin,N. 2009. Ilmu Kesehatan Masyarakat: Teori dan Aplikasi. Jakarta: Penerbit Salemba Medika.

Dainur. 1995. Materi-Materi Pokok Ilmu Kesehatan Masyarakat. Jakarta: Widya Medika.

Slamet, J.S. 2009. Kesehatan Lingkungan.Yogyakarta:Gadjah Mada University. Sobarudin, A. 2012.Pengertian Kebiasaan (custom). http://www.bisosial.com/2012/11/kebias aan-custom.html02 Desember 2013(13:00).

Suparmin, S. 2002. Pembuangan Tinja \& Limbah Cair.Jakarta: ECG.

Sutedjo. 2003. Analisis Perilaku Masyarakat dalam Penggunaan Jamban Keluarga pada Dua Desa di Kabupaten Rembang. Tesis. Program Pasca Sarjana Universitas Diponegoro. Semarang.

Laporan Nasional Riset Kesehatan Nasional (Riskesdas) Tahun 2010. Jakarta. Chandra, B. 2007. Pengantar Kesehatan Lingkungan. Jakarta: EGC.

Warsito. 1996. Kakus Sederhana Bagi Masyarakat Desa.Jakarta: Kanisius.

Widaryoto, 2003. Faktor-faktor yang Berhubungan dengan Praktik Penggunaan Jamban pada Kepala Keluarga yang Memiliki Jamban di Kecamatan Kepahiang Kabupaten Rejang Lebong Provinsi Bengkulu. Skripsi. FKM UI. Jakarta.

Widiati, S. 2001. Planet Kita Kesehatan Kita: Laporan Komisi WHO MengenaiKesehatan dan Lingkungan. Yogyakarta: UGM Press 